\title{
含中氮狮有机太阳能电池染料敏化剂的分子设计
}

\author{
侯丽梅 1,2 温 智 ${ }^{2,3}$ 李银祥 ${ }^{2}$ 胡华友 ${ }^{2}$ 阚玉和 $2,3, *$ 苏忠民1,3,* \\ ('延边大学理学院化学系, 吉林 延吉 133002 ; 江苏省低维材料化学重点建设实验室, 淮阴师范学院化学化工 \\ 学院, 江苏淮安 $223300 ;{ }^{3}$ 东北师范大学化学学院, 功能材料化学研究所, 长春 130024)
}

摘要：采用密度泛函理论(DFT)和含时密度泛函理论(TD-DFT)方法研究了 9 个新的中氮荫[3,4,5-ab]异吲哚 (INI)为给体的染料敏化剂性质. 对影响电池效率的光捕获效率、电子注入、染料再生和电荷复合等重要因素 与D5和D9染料进行了对比. 计算表明, 设计的INI系列敏化剂在440-500 nm内有最大吸收峰, 表现出明显的电 荷分离特征, INI2具有比D9染料更高的最大理论短路电流. Fukui反应指数计算指出INI2的亲核加成最易实现. 染料分子在二氧化钛(101)面吸附计算表明, 染料INI2 以间接注入途径实现电子注入. 综合计算结果, 中氮蒱 INI染料有希望作为性能优良的染料敏化剂而得到应用.

关键词: 中氮狮[3,4,5-ab]异吲哚; 染料敏化太阳能电池; 电子吸收光谱; 光捕获效率; 密度泛函理论; 含时密度泛函理论

中图分类号: 0641

\section{Molecular Design of Indolizine Derivative as Sensitizers for Organic Dye-Sensitized Solar Cells}

\author{
HOU Li-Mei ${ }^{1,2}$ WEN Zhi ${ }^{2,3} \quad$ LI Yin-Xiang ${ }^{2} \quad$ HU Hua-You ${ }^{2}$ \\ KAN Yu-He $\mathrm{e}^{2,3, *} \quad$ SU Zhong-Min ${ }^{1,3, *}$ \\ ( ${ }^{1}$ Department of Chemistry, School of Science and Engineering, Yanbian University, Yanji 133002, Jilin Province, P. R. \\ China; ${ }^{2}$ Jiangsu Province Key Laboratory for Chemistry of Low-Dimensional Materials, School of Chemistry and \\ Chemical Engineering, Huaiyin Normal University, Huai'an 223300, Jiangsu Province, P. R. China; ${ }^{3}$ Institute of \\ Functional Material Chemistry, Faculty of Chemistry, Northeast Normal University, Changchun 130024, P. R. China)
}

\begin{abstract}
Nine new D- $\pi$-A metal-free sensitizers INI1-INI9 with indolizino [3,4,5-ab] isoindole (INI) as electronic donor were investigated using the density functional theory (DFT) and time-dependent DFT calculations. Compared to D5 and D9, some major factors affecting the performance of the cell, including light harvesting, electron injection, dye regeneration, and charge recombination are taken into consideration. Calculations show that these novel INI-based sensitizers have an absorption maximum at $440-500 \mathrm{~nm}$ when $\pi$ conjugated bridge attached at different position of aromatic ring and an excellent charge separation characters. INI2 shows better performance than that of D9 due to the theoretical maximum short-circuit current density of $13.26 \mathrm{~mA} \cdot \mathrm{cm}^{-2}$. Fortunately, condensed Fukui function calculation suggested that the INI2 be easiest to obtain due to a largest nucleophilic index at 2 position of INI aromatic ring. Based on the calculations of dyes adsorption on $\mathrm{TiO}_{2}$ cluster, indirect electron injection may be the main path from dye to $\mathrm{TiO}_{2}$ for INI2 and D5. Our calculations indicate that the INI dyes will be promising candidates for fabrication of the high performance dye-sensitized solar cells.
\end{abstract}

Received: March 9, 2015; Revised: May 20, 2015; Published on Web: May 21, 2015.

"Corresponding authors. SU Zhong-Min, Email: zmsu@nenu.edu.cn; Tel: +86-433- 85684009. KAN Yu-He, Email: kyh@hytc.edu.cn. The project was supported by the National Natural Science Foundation of China (21131001, 21273030, 21203019, 21203020).

国家自然科学基金(21131001, 21273030, 21203019, 21203020)资助项目

(C) Editorial office of Acta Physico-Chimica Sinica 
Key Words: Indolizino [3,4,5-ab] isoindole; Dye-sensitized solar cell; Electronic absorption spectrum; Light-harvesting efficiency; Density functional theory; Time-dependent density functional theory

\section{1 引言}

近年来, 化石燃料消耗的增长以及环境污染引 起了人们对绿色能源的广泛关注和深入研究. 太阳 能作为一种取之不尽、用之不竭的可再生能源, 具 有清洁无害、利用成本低廉、可直接开发和利用 且不受地理条件限制等诸多优点, 受到了科学家们 的关注. 1991年Grätzel研究小组'采用高比表面积的 纳米多孔 $\mathrm{TiO}_{2}$ 膜电极, 以金属钉多吡啶配合物做敏 化染料并选用 $\mathrm{I}_{3}^{-} / \mathrm{I}^{-}$氧化还原电对的电解质溶液, 首 次研制出结构简单、易于制造及生产成本低等突 出优点的新型太阳能电池-染料敏化太阳能电池 (DSSCs), 其能量转化效率超过 $7.1 \%$. 虽然目前 DSSCs 的最高转换效率约在 $12.3 \%$ 左右, ${ }^{2}$ 但相对无 机硅材料还是比较低, 因此进一步提高能量转换效 率成为当前有机光伏材料研究的重要任务之一.

在光敏剂中, 钉化合物(如N3和N719)的光电转 化效率达到了 $10 \%$. 尽管如此, 科学家们更青睐于制 备简单经济且环保低污染的纯有机染料敏化剂. ${ }^{3-5}$ 大量无金属的有机染料作为染料敏化剂陆续被研 究, 如三苯胺、 ${ }^{6}$ 香豆素、 ${ }^{7}$ 部花菁、 ${ }^{8}$ 吩噻嗪、 ${ }^{9}$ 卟 啉类 ${ }^{10}$ 以及四硫富瓦烯 $11-13$ 等为给体的给体 $-\pi$ 共轭桥受体(D- $\pi-A)$ 型敏化剂, 但其光电转换效率大多数仍 低于N3系列染料. 吲哚啉具有比三苯胺更强的给电 子能力, 最近, 基于吲哚为给体的有机染料敏化剂 的研究引起关注, 其中D $149^{14}$ 和WS- $9^{15}$ 的DSSCs达到 了高于 $9 \%$ 的能量转换效率. 中氮茚 $[3,4,5-\mathrm{ab}]$ 异吲哚 $(\mathrm{INI})^{16}$ 是含有 $\mathrm{N}$ 原子的杂环化合物, 此系列杂环化合 物在 $400 \mathrm{~nm}$ 以上有较强吸收, 其苂光量子效率已高 达 $90 \%$, 该类化合物具有较低的电离势, 因此可以预 期作为染料分子给体. 目前中氮狮 [3,4,5-ab]异吲哚 衍生物作为染料敏化剂在DSSC方面还未见报道. 本文在实验研究的典型 $D-\pi-A$ 型染料 $\mathbf{D 5}{ }^{17}$ 及 D $9^{18}$ 基 础上, 以INI取代三苯胺, 考虑不同位置桥联, 设计 了系列INI为给体、噻吩乙烯为共轭链以及氰基羧 酸为受体的D- $\pi$-A型有机光敏染料(图1), 采用密度 泛函理论(DFT) 和含时密度泛函理论(TD-DFT)方法 研究了染料分子的几何结构、电子跃迁性质、激 子结合能和电子注入驱动力, 探讨其作为染料敏化 剂的性质.

\section{2 计算方法}

采用杂化密度泛函B3LYP ${ }^{19} / 6-31 \mathrm{~g}^{*}$ 方法对染料 分子基态的几何构型进行全优化, 频率计算分析验 证得到的几何构型均为稳定结构. 为有效评价设计 体系分子的电子吸收光谱, 首先以D5和D9考察不同 密度泛函对光谱的影响, 泛函选择全局杂化密度泛 函B3LYP(20\% HF交换), ${ }^{19} \mathrm{PBE} 0(25 \% \mathrm{HF}$ 交换 $),{ }^{20}$ MPW1K $(42.8 \% \mathrm{HF} \text { 交换 })^{21}$ 和M06- $\mathrm{HF}(100 \% \mathrm{HF} \text { 交换 })^{22}$ 以及 CAM-B3LYP ${ }^{23} L C-\omega P B E^{24}$ 和 $\omega B$ 97XD ${ }^{25}$ 等范围 分离泛函, 采用TD-DFT结合线性响应极化连续溶 剂化模型(LR-PCM $)^{26}$ 计算在乙醇溶剂下的电子吸收 光谱. 与实验光谱结果对比, $\omega \mathrm{B} 97 \mathrm{XD} / 6-31 \mathrm{~g}$ *计算结 果与实验结果吻合最好. 因此我们采用 $\omega B$ B $97 X D / 6-$ $31 \mathrm{~g}^{*}$ 方法并结合LR-PCM计算设计染料分子的垂直 跃迁能并预测其电子吸收光谱. 采用Multiwfn程序 ${ }^{27}$ 分析了轨道重叠及电荷转移的关系. 为表明电子注 入特征, 在B3LYP/6-31 g*方法优化的结构基础上, 采 用TD- $\omega$ B 97XD/6-31g 结合PCM模型 (乙醇溶剂) 计 算了染料 $-\mathrm{TiO}_{2}$ 的电子结构、相互作用和电子吸收 光谱, 平衡计算结果可靠性和计算消耗, 以 $\left(\mathrm{TiO}_{2}\right)_{9}$ 簇 作为半导体纳米粒子模拟染料在锐钛矿型团簇 (101) 面的吸附, $\left(\mathrm{TiO}_{2}\right)_{9}$ 模型可以定性分析染料$\mathrm{TiO}_{2}$ 类体系的电子吸收光谱. ${ }^{28-30}$ 为验证结果可靠性, 我们采用同样的TDDFT方法计算染料- $\left(\mathrm{TiO}_{2}\right)_{48}$ 复合 物的三个最低跃迁能. 染料- $\left(\mathrm{TiO}_{2}\right)_{48}$ 初始结构参考 Pastore和Angelis研究的最大结合能吸附位置 ${ }^{31}$ 而建 立, 几何优化采用PBEsol泛函结合模守恒噟势DZP

(A)

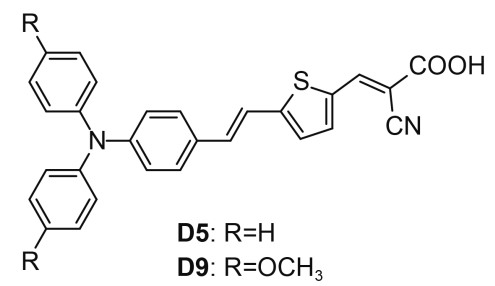

(B)

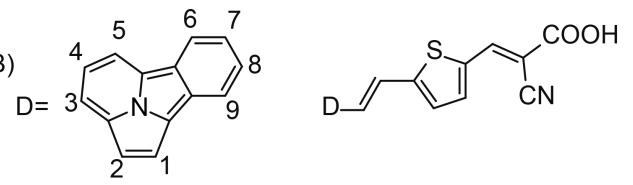

图1 染料D5、D9(A)和INI1-INI9(B)的结构

Fig.1 Structures of dyes D5, D9 (A), and INI1-INI9 (B) 
基组在SIESTA程序 ${ }^{32}$ 中完成, 相应的实空间格点值 取 $250 \mathrm{Ry} .{ }^{32,33}$ 以上计算中除MPW1K泛函计算使用 Gaussian 03程序外, 其他计算均采用Gaussian 09程 序包完成.

\section{3 结果与讨论}

\section{1 电子结构}

采用B3LYP/6-31 $\mathrm{g}^{*}$ 方法对设计 INI类染料分子 的九个化合物(1-9)进行几何结构优化, 除INI3 和 INI9化合物的给体与共轭链有明显扭曲角(分别为 $10.7^{\circ}$ 和 $\left.23.8^{\circ}\right)$ 外, 其他化合物优化得到的最稳定几 何构型均为近平面结构. 图2列出了B3LYP/6-31g*优 化的几何构型下D5和D9以及INI系列九个化合物的 最高占据轨道 $(\mathrm{HOMO}, \mathrm{H})$ 和最低未占据轨道 (LUMO, L) 能级. D9与D5对比可知, 4-甲氧基修饰 使前线轨道能级提高, 对 $\mathrm{HOMO}$ 能级影响更大, 导 致能隙相对减小 $0.14 \mathrm{eV}$. 而对于本文设计的中氮狮 染料体系, INI2 与D5 前线轨道能级相当, 其他分子 的前线轨道能级相对降低 $0.07-0.30 \mathrm{eV}$. 中氮狮芳环 桥联位置不同对染料分子的前线轨道能级均有影 响, HOMO和LUMO能级变化分别为 0.32 和 $0.31 \mathrm{eV}$, 能隙范围为2.39-2.59 eV, 其中INI1和INI8能隙最 大，而并非INI3 和INI9，说明空间效应并非是能隙 大小的决定因素. 图中虚线为 $\mathrm{TiO}_{2}$ 半导体导带底相 对真空能级 $(-4.00 \mathrm{eV})^{34}$ 和 $\mathrm{I}^{-} / \mathrm{I}_{3}^{-}$氧化还原电对的还 原电位 $(-4.85 \mathrm{eV}) .{ }^{35}$ 计算的 11 种化合物的LUMO能 级均高于半导体的导带底相对能级 $\left(E_{\mathrm{CB}}\right)$, 确保激发 的染料电子能够自发向 $\mathrm{TiO}_{2}$ 半导体导带中注入, 而

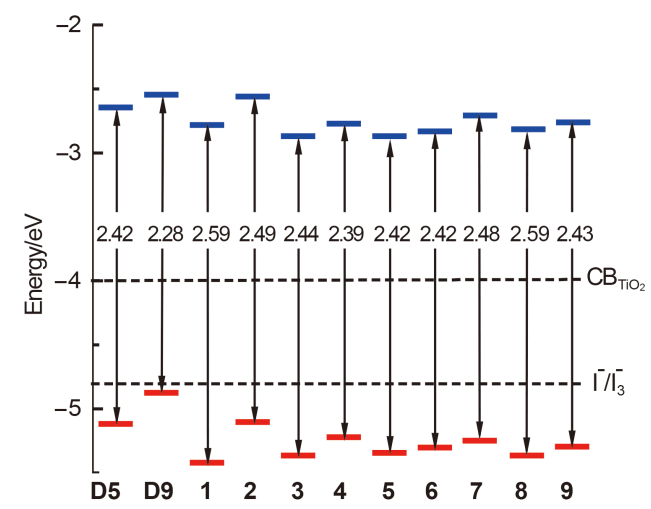

图2 用B3LYP/6-31 $\mathrm{g}^{*}$ 方法计算的体系D5, D9以及设计体系 INI1-9的前线轨道能级图

Fig.2 Frontier orbital energy level diagram of D5, D9 and designed dyes INI1-9 by B3LYP/6-31 ${ }^{*}$ method

$\mathrm{CB}$ : conduction band
所有染料分子的 $\mathrm{HOMO}$ 能级都低于 $\mathrm{I}^{-} / \mathrm{I}_{3}^{-}$对的氧化还 原电位, 因而使失去电子的氧化态染料容易被氧化 还原电对还原得到电子而再生.

前线轨道分布与敏化剂的吸收光谱和电荷转 移性质紧密相关. 如图S1(Supporting Information)所 示, 与D5和D9(与D5分布基本相同而未列出)前线轨 道分布特征类似, 所有敏化剂HOMO上的电子密度 离域分布在给体及 $\pi$ 共轭桥部分, 而LUMO则主要定 域在 $\pi$-桥和受体部分. 这种轨道分布特征使敏化剂 在光激发后产生电荷转移跃迁, 从而有利于电子-空 穴分离. 值得注意的是, INI1、INI5 和INI8 中 $\mathrm{HOMO}$ 的 $\pi$ 桥部分电子密度相对较小, HOMO 与 LUMO电子密度重叠积分较小而影响第一激发的吸 收强度. 此外, 所有染料的吸附基团 $(-\mathrm{COOH})$ 对 LUMO轨道也有明显的贡献, 有助于增强敏化剂与 半导体表面的电子耦合, 促进电子注入到半导体 中. ${ }^{36}$

\section{2 可见吸收光谱及激发态电荷转移}

敏化剂在可见及近红外区的吸收范围和吸收 强度对提高光捕获效率从而改善DSSC的性能至关 重要. 目前, TD-DFT对于敏化剂的吸收性质研究及 预测已可以得到可靠的结果, ${ }^{37}$ 然而研究体系往往 对泛函的选择有较强的依赖性, 尤其是对具有明显 电荷转移特征激发态, ${ }^{38,39}$ 纯泛函和低 $\mathrm{HF}$ 交换成分的 全局杂化泛函的TD-DFT计算通常会过低估计激发 能, 且容易过高估计电荷转移程度, 而范围分离泛 函是解决此问题的理想方法..$^{40-42}$ 潘石等 43,44 通过改变 和修饰D5 分子中的共轭桥设计系列长波长吸收染 料, 用含时密度泛函理论B3LYP/6-31 $\mathrm{g}^{*}$ 方法考虑溶 剂效应预测其最大吸收波长, 发现TD-B3LYP/6-31g* 结果与实验存在较大偏差. 为选取合适的密度泛函 评估研究体系的激发能和吸收光谱特征, 我们以文 献中报道的D5和D9染料作为参照体系, 选择典型的 杂化密度泛函B3LYP、PBE0、MPW1K、M06HF以及CAM-B3LYP、LC- $\omega$ PBE和 $\omega B$ B $7 X D$ 等范围 分离泛函, 采用TD-DFT结合LR-PCM溶剂化模型计 算二者在乙醇溶剂下的紫外-可见光谱. 用Gauss 函 数拟合各种泛函计算的电子吸收光谱与实验结果 对比列于图3. 可以看出, B3LYP和PBE0泛函都显著 低估了第一激发能(D5: 分别为 0.76 和 $0.65 \mathrm{eV} ; \mathbf{D 9}$ : 分别为 0.78 和 $0.67 \mathrm{eV})$, 随着 $\mathrm{HF}$ 交换成分的增加, 最 低跃迁能逐渐增大, 即第一最大吸收波长蓝移, MPW1K泛函计算D5的最低跃迁能低估了 $0.30 \mathrm{eV}$, 这与Pastore等 ${ }^{41}$ 计算结果一致, 他们采用MPW1K泛 

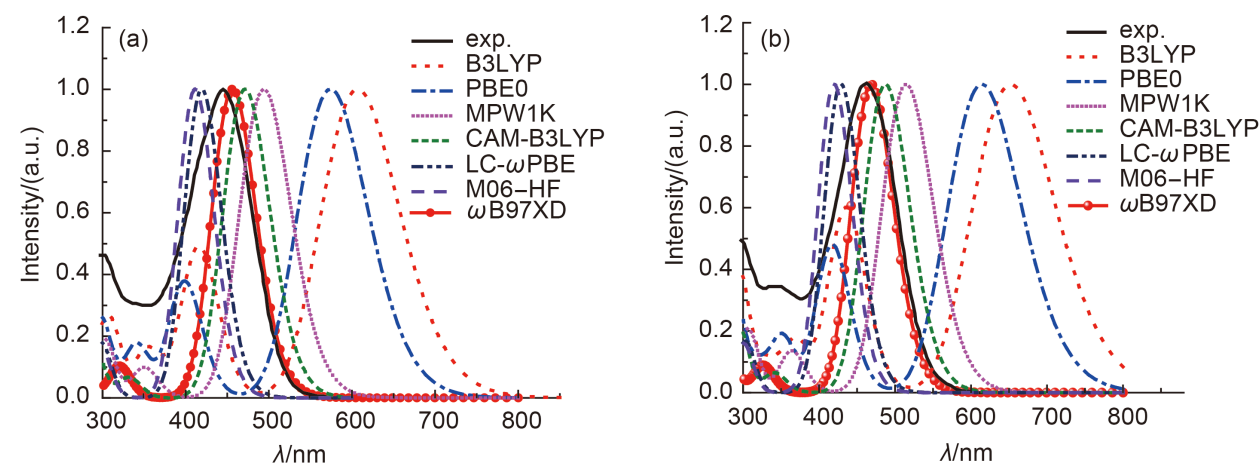

图3 实验和不同密度泛函方法在6-31 ${ }^{*}$ 基组水平乙醇溶剂下计算拟合的D5 (a)和D9 (b)电子吸收光谱的比较

Fig.3 Comparison between experimental and theoretical absorption spectra of D5 (a) and D9 (b) obtained with various functional at $6-31 \mathrm{~g}^{*}$ basis set level of density functional theory in ethanol solvent

函在气相下计算低估 $0.11 \mathrm{eV}$. 正如预期的, $100 \% \mathrm{HF}$ 交换成分的Minnesota M06-HF杂化泛函结果更加 蓝移, 高估实验值 $0.21 \mathrm{eV}$. 与上述杂化泛函结果相 比，三种范围分离泛函结果都有明显改善，LC$\omega \mathrm{PBE}$ 泛函计算值相对实验值高估 $0.15 \mathrm{eV}(\mathbf{D 5})$ 和 $0.21 \mathrm{eV}(\mathrm{D} 9)$, 而CAM-B3LYP泛函相对实验值低估 $0.18 \mathrm{eV}(\mathbf{D 5})$ 和 $0.13 \mathrm{eV}(\mathbf{D} 9), \omega \mathrm{B} 97 \mathrm{XD}$ 方法给出结果 更接近实验值 (D5: 0.09 eV; D9: $0.03 \mathrm{eV})$. 因此, 以 下我们采用 $\omega \mathrm{B} 97 \mathrm{XD} / 6-31 \mathrm{~g}$ 方法结合PCM溶剂化模 型计算INI九个染料在乙醇中的电子吸收光谱进行 讨论.

图4给出了模拟得到吸收光谱及 $\mathrm{AM} 1.5 \mathrm{G}$ 太阳 光子通量谱(AM1.5G, ASTM_G173). 从图4可看出, 设计的敏化剂吸收光谱与D5及D9在435-495 $\mathrm{nm}$ 可 见区内有较强的吸收带, D9较D5略有红移且强度相 当, 很好地重复了实验结果. ${ }^{18}$ 值得注意的是, INI2在 $495 \mathrm{~nm}$ 处有与D9相当强度的吸收, 最大吸收 峰较D5和D9的吸收光谱明显红移(较D5红移 $39 \mathrm{~nm}$, 较D9红移 $26 \mathrm{~nm})$, INI3 和INI4也展现出略大于D5最 大吸收波长, 预示着较好的光捕获效率. 表1列出所 有研究敏化对应于第一激发态 $S_{1}$ 的最大吸收波长 $\left(\lambda_{\max }\right)$ 、振子强度 $(f)$ 、主要跃迁组态、电荷转移长 度 $\left(D_{\mathrm{CT}}\right)$ 、电子跃迁偶极距 $\mu_{\mathrm{cg}}$ 和激子结合能 $E_{\mathrm{b}}$. 对于 敏化剂INI2, 尽管其能隙大于D5和D9, 但由于较大 的激子结合能使其跃迁能明显小于D5和D9, INI3 也 具有类似的特点. INI2较强的最大吸收主要是由于 其具有最大的跃迁偶极矩.

从表 1 可知, 所有染料的最强吸收峰可以归属 为基态 $S_{0} \rightarrow S_{1}$ 的跃迁, 均具有相似的多组态跃迁特 征, 即从HOMO到LUMO的主要跃迁与HOMO-1到 LUMO的次要贡献, 结合附图1中前线轨道分布, 我
们可以初步判断最低跃迁态为电荷转移激发态. 为

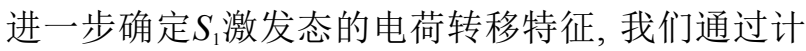
算正负电荷质心距 $C_{+}(\mathrm{r}) / C_{-}(\mathrm{r})$ 及电荷转移长度 $C_{\mathrm{CT}}{ }^{45}$ 进行表征, 并对比了通用杂化泛函B3LYP和范围分 离泛函 $\omega B$ B97XD两种结果, 如图S2 所示. 显然, 两种 计算方法一致表明, 电荷密度减小的蓝色区域 $(C)$ 主 要集中在给体一侧, 而电荷密度增加的绿色区域 $\left(C_{+}\right)$主要集中在 $\pi$ 共轭桥上, 证实这些 $\mathrm{D}-\pi-\mathrm{A}$ 型染料 的 $S_{1}$ 激发态都具有明显的分子内电荷转移特征. 从 表 1 得知这些敏化剂的电荷转移长度 $D_{\mathrm{CT}}$ 的顺序为 INI1 $\approx$ INI5 $<$ INI8 $<$ INI6 $<$ INI3 $<$ INI9 $\approx$ INI2 $<$ INI7 $<$ INI4 $\approx \mathbf{D 5}<\mathbf{D 9}$, 而激子结合能 $E_{\mathrm{b}}$ 呈现出与 此近似相反的大小趋势, 就D5和D9而言, 较大 $D_{\mathrm{CT}}$ 以 及较小的 $E_{\mathrm{b}}$ 可能是 $\mathbf{D 9}$ 的单色光光电转换效率 (IPCE) 较大的原因之一, $\mathrm{Kim}$ 等 ${ }^{36}$ 发现, 染料最大的 IPCE与 $E_{\mathrm{b}}$ 之间的确存在一个反比的线性关系. 这可 以理解为激子结合能较小, 对激子的库仑束缚力较

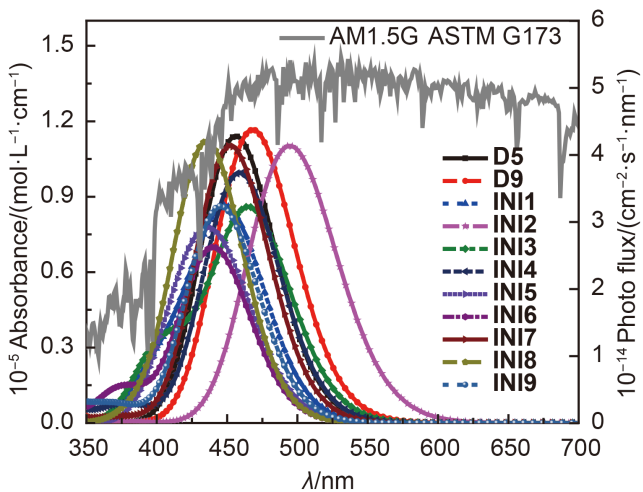

图4 在TD-PCM- $\omega$ B97XD/6-31g ${ }^{*}$ 水平下计算模拟研究染料 INI1-9在乙醇溶剂中的电子吸收光谱

Fig.4 Electronic absorption spectra of D5, D9 and INI1-9 calculated in ethanol solvent withTD-PCM- $\omega$ B97XD/6-31 ${ }^{*}$ level of theory 
表1 在乙醇溶剂中用TD-PCM- $\omega$ B97XD/6-31 $\mathrm{g}^{*}$ 方法计算的D5, D9, INI1-9D最大吸收波长 $\left(\lambda_{\max }\right)$ 、振子强度 $(f)$ 、跃迁贡献、 电荷转移长度 $\left(\boldsymbol{D}_{\mathrm{CT}}\right)$ 、跃迁偶极矩 $\left(\boldsymbol{\mu}_{\mathrm{cg}}\right)$ 和激子结合能 $\left(\boldsymbol{E}_{\mathrm{b}}\right)$

Table 1 Calculated maximun absorption wavelength $\left(\lambda_{\max }\right)$, oscillator strength $(f)$, and transition nature, length of CT $\left(D_{\mathrm{CT}}\right)$, transition dipole moment $\left(\mu_{\mathrm{eg}}\right)$, and exciton binding energy $\left(E_{\mathrm{b}}\right)$ of D5, D9 and INI1-9 at TD-PCM- $\omega$ B97XD/6-31 ${ }^{*}$ level of theory in ethanol solvent

\begin{tabular}{cccccccc}
\hline Dye & State & $\lambda_{\text {max }} / \mathrm{nm}$ & $f$ & Transition contributions & $D_{\mathrm{cT}} / \mathrm{nm}^{\mathrm{b}}$ & $\mu_{\mathrm{eg}} /($ a.u. $)$ & $E_{\mathrm{b}} / \mathrm{eV}$ \\
\hline D5 & $S_{0} \rightarrow S_{1}$ & $455(441)^{\mathrm{a}}$ & 1.5731 & $\mathrm{H} \rightarrow \mathrm{L}(71 \%), \mathrm{H}-1 \rightarrow \mathrm{L}(21 \%)$ & 0.42 & 23.6 & 2.79 \\
D9 & $S_{0} \rightarrow S_{1}$ & $468(462)^{\mathrm{a}}$ & 1.6089 & $\mathrm{H} \rightarrow \mathrm{L}(67 \%), \mathrm{H}-1 \rightarrow \mathrm{L}(25 \%)$ & 0.44 & 24.8 & 2.67 \\
INI1 & $S_{0} \rightarrow S_{1}$ & 450 & 1.1532 & $\mathrm{H} \rightarrow \mathrm{L}(53 \%), \mathrm{H}-1 \rightarrow \mathrm{L}(34 \%)$ & 0.30 & 17.1 & 3.01 \\
INI2 & $S_{0} \rightarrow S_{1}$ & 494 & 1.5208 & $\mathrm{H} \rightarrow \mathrm{L}(85 \%)$ & 0.39 & 24.7 & 2.94 \\
INI3 & $S_{0} \rightarrow S_{1}$ & 466 & 1.1695 & $\mathrm{H} \rightarrow \mathrm{L}(75 \%), \mathrm{H} \rightarrow \mathrm{L}+1(12 \%)$ & 0.35 & 17.9 & 2.93 \\
INI4 & $S_{0} \rightarrow S_{1}$ & 459 & 1.3752 & $\mathrm{H} \rightarrow \mathrm{L}(75 \%), \mathrm{H}-1 \rightarrow \mathrm{L}(15 \%)$ & 0.42 & 20.7 & 2.78 \\
INI5 & $S_{0} \rightarrow S_{1}$ & 447 & 0.7167 & $\mathrm{H} \rightarrow \mathrm{L}(49 \%), \mathrm{H}-1 \rightarrow \mathrm{L}(33 \%)$, & 0.30 & 10.5 & 2.91 \\
INI6 & $S_{0} \rightarrow S_{1}$ & 440 & 0.9640 & $\mathrm{H} \rightarrow \mathrm{L}(58 \%), \mathrm{H}-1 \rightarrow \mathrm{L}(19 \%)$, & 0.34 & 14.0 & 2.81 \\
INI7 & $S_{0} \rightarrow S_{1}$ & 452 & 1.5215 & $\mathrm{H} \rightarrow \mathrm{L}(67 \%), \mathrm{H}-1 \rightarrow \mathrm{L}(18 \%)$ & 0.40 & 22.6 & 2.82 \\
INI8 & $S_{0} \rightarrow S_{1}$ & 436 & 1.5288 & $\mathrm{H} \rightarrow \mathrm{L}(39 \%), \mathrm{H}-1 \rightarrow \mathrm{L}(42 \%)$ & 0.32 & 21.9 & 2.83 \\
INI9 & $S_{0} \rightarrow S_{1}$ & 445 & 1.1894 & $\mathrm{H} \rightarrow \mathrm{L}(70 \%), \mathrm{H}-1 \rightarrow \mathrm{L}(20 \%)$ & 0.39 & 17.4 & 2.83 \\
\hline
\end{tabular}

${ }^{\mathrm{a}} \mathrm{H}$ represents the highest occupied molecular orbital (HOMO), L represents the lowest unoccupied molecular orbital (LUMO), ${ }^{\mathrm{b}}$ Experimental values were obtained from Ref. 18.

弱, 电荷分离较为容易, 表现为较长的 $D_{\mathrm{CT}}$, 从而有利 于光电流的产生. 候选的敏化剂INI4和INI7具有和 $\mathbf{D 5}$ 相当的 $E_{\mathrm{b}}$ 与 $D_{\mathrm{CT}}$, 而 INI2 的 $D_{\mathrm{CT}}$ 与 $E_{\mathrm{b}}$ 相比于 $\mathbf{D 9}$ 则分 别下降 $0.05 \mathrm{~nm}$ 和增加了 $0.27 \mathrm{eV}$, 因此, 可以对候选 敏化剂进行进一步化学修饰降低 $E_{\mathrm{b}}$, 从而改善其IPCE.

另外, 对比 B $3 L Y P$ 和 $\omega B$ 97XD方法计算的 $D_{\mathrm{CT}}$ 和 重叠指数 $\Lambda$ (见Supporting Information表 $\mathrm{S} 1$ ) 可看出, B3LYP方法比 $\omega$ B $97 X D$ 方法计算的 $D_{\text {C }}$ 值高 $0.2 \mathrm{~nm}$ 左 右, 因此明显高估了电荷转移程度, 表明这类体系 激发电荷转移态的计算中采用范围分离泛函的必 要性.

\section{3 光捕获效率与短路电流密度}

短路电流密度 $\left(J_{\mathrm{sc}}\right)$ 是决定染料敏化太阳能电池 性能的关键参数, 可通过对标准的 AM1.5G太阳光 子通量 $\varphi_{\text {ph.AM1.5G }}(\lambda)$ 与单色光光电转换效率(IPCE) 之间的乘积函数积分得到: ${ }^{46}$

$$
\begin{aligned}
& J_{\mathrm{sc}}=\mathrm{e} \int_{\lambda} \operatorname{IPCE}(\lambda) \varphi_{\mathrm{ph} . \mathrm{AM} 1.5 \mathrm{G}}(\lambda) \\
& \text { 而IPCE可以表示为: }
\end{aligned}
$$

$$
\operatorname{IPCE}(\lambda)=\operatorname{LHE}(\lambda) \Phi_{\text {inj }} \eta_{\text {reg }} \eta_{\text {coll }}
$$

其中, $\Phi_{\mathrm{inj}}$ 是电子注入效率, $\eta_{\mathrm{reg}}$ 是敏化剂的再生效率, $\eta_{\text {coll }}$ 则是电荷收集效率. 光捕获效率 $\operatorname{LHE}(\lambda)$ 可由下式 计算得到: ${ }^{47}$

$$
\operatorname{LHE}(\lambda)=1-10^{-\varepsilon(\lambda) c d}
$$

其中, $\varepsilon(\lambda)$ 是敏化剂的摩尔吸光系数, $c$ 是敏化剂在半 导体表面的吸附浓度; $d$ 则是半导体薄膜的厚度. 为 方便与实验对比, 半导体薄膜的厚度取 $12 \mu \mathrm{m}$, 敏化 剂在半导体表面的吸附浓度为 $0.3 \mathrm{~mol} \cdot \mathrm{L}^{-1}$. 图 5 给出 了计算得到的 $\operatorname{LHE}(\lambda)$, 可以看出INI2、INI3、 INI4 和INI7 表现出较大的LHE，并且LHE大于 0.95 的吸收波长范围也足够宽, 尤其是INI2, 明显超 出了D9.

假定电子注入、敏化剂再生和电荷收集的效 率均为 1 , 则可以通过公式(1)计算得到最大理论短 路电流 $J_{\mathrm{sc}}^{\max }$, 用来定量反映敏化剂总光捕获能力. ${ }^{48,49}$ 计算得到的所研究敏化剂最大理论 $J_{\mathrm{sc}}^{\max }$ 列于表 $2, \mathbf{D 5}$

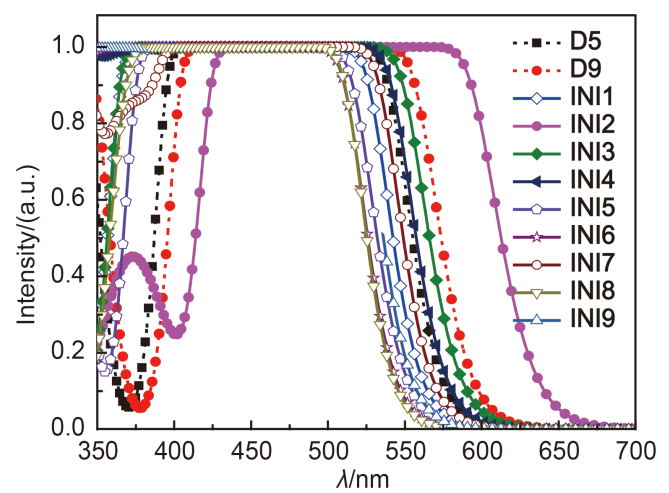

图5 计算的敏化剂D5、D9和INI1-9的光捕获效率LHE $(\lambda)$ Fig.5 Calculated light harvest efficiency LHE $(\lambda)$ of D5, D9 and INI1-9 dyes 
和D9计算值分别为 9.78 和 $10.98 \mathrm{~mA} \cdot \mathrm{cm}^{-2}$, 与实验值 12.00 和 $14.00 \mathrm{~mA} \cdot \mathrm{cm}^{-2}$ 吻合较好. 令人兴奋的是, 因 其明显的吸收红移在所研究敏化剂中具有最强的 光捕获能力, 敏化剂INI2最大理论短路电流达到 $13.26 \mathrm{~mA} \cdot \mathrm{cm}^{-2}$, 比D9高 $2.28 \mathrm{~mA} \cdot \mathrm{cm}^{-2}$, INI3 和 INI4最大理论短路电流也超过了 $10 \mathrm{~mA} \cdot \mathrm{cm}^{-2}$, 高于 D5染料. 而敏化剂INI8因其吸收波长相对最短具有 最低的理论短路电流. 因此, 中氮狮INI为给体的染 料可以作为一种新的有潜力的高光电转换效率的 染料敏化剂.

\section{4 电子注入驱动力和染料再生能力}

由公式(2)可知, 增大电子注入效率 $\Phi_{\mathrm{inj}}$ 和敏化 剂的再生效率 $\eta_{\mathrm{reg}}$ 也是增强短路电流的关键因素, $\Phi_{\mathrm{inj}}$ 可用电子注入驱动力 $\left(\Delta G_{\mathrm{inj}}\right)$ 初步评估, 染料再生 效率 $\eta_{\mathrm{reg}}$ 则依赖于反向电子转移与敏化剂再生之间 的竞争, 足够高的染料再生驱动力 $\Delta G_{\mathrm{reg}}$ 和较低的电 荷复合驱动力 $\Delta G_{\mathrm{rec}}$ 是敏化剂有效再生的必要条件. $\Delta G_{\mathrm{inj}} 、 \Delta G_{\mathrm{reg}}$ 和 $\Delta G_{\mathrm{rcc}}$ 可分别用以下公式 ${ }^{50,51}$ 解得:

$$
\begin{aligned}
& \Delta G_{\text {inj }}=E_{\mathrm{LUMO}}-E_{\mathrm{CB}} \\
& \Delta G_{\mathrm{rec}}=E_{\mathrm{CB}}-E_{\mathrm{HOMO}} \\
& \Delta G_{\mathrm{reg}}=E_{\text {redox }}^{\mathrm{I}_{3}^{-} / \mathrm{I}^{-}}-E_{\mathrm{HOMO}}
\end{aligned}
$$

式中, $E_{\mathrm{CB}}$ 为半导体的导带能量 (本文采用实验值 $\left.-4.00 \mathrm{eV}^{34}\right), E_{\mathrm{redox}}^{\mathrm{I}_{3}^{-} / \mathrm{I}^{-}}$为 $\mathrm{I}_{3}^{-} / \mathrm{I}^{-}$的氧化还原电位 $-4.85 \mathrm{eV}^{35}$.

计算结果列于表 2 中, 计算表明 D9 比D5 的 $\Delta G_{\mathrm{inj}}$ 大 $0.1 \mathrm{eV}, \mathbf{I N I} 2$ 的 $\Delta G_{\mathrm{inj}}$ 与 D9相当, 其他INI敏化 剂的 $\Delta G_{\mathrm{inj}}$ 在1.10-1.27 eV之间, 与参考染料 D5相比 最大降低 $0.23 \mathrm{eV}$. 对于染料再生驱动力, 计算出的
D5的 $\Delta G_{\mathrm{reg}}$ 比D9的高 $0.24 \mathrm{eV}$, 表明敏化剂的再生效 率并不是D5具有较低光电转换的决定性因素, 而设 计的INI敏化剂的 $\Delta G_{\mathrm{reg}}$ 都大于或接近D5. 电荷复合 驱动力计算表明, D9最小, INI2 比D5 小 $0.02 \mathrm{eV}$, 其 次是INI4, 其他敏化剂相对高出 $0.12-0.20 \mathrm{eV}$. 因此, INI2 具有较高的电子注入驱动力、电荷再生驱动 力和较低的电荷复合驱动力, 而具有作为染料敏化 剂的潜质.

\section{5 染料在 $\mathrm{TiO}_{2}$ 表面的吸附}

染料与 $\mathrm{TiO}_{2}$ 半导体界面的结构与激发电子态决 定着电子从激发态染料向半导体导带的注入效率, 我们以D5及综合性能表现良好的INI2 为代表进一

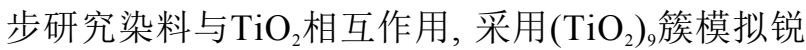
钛矿的(101)面, 敏化剂的羧酸吸附基团以最稳定的

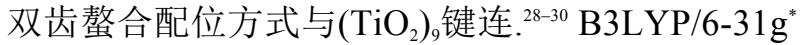
优化的稳定结构显示, D5-TiO $_{2}$ 中羧酸氧与 $\mathrm{Ti}$ 形成的 Ti-O键距离为 0.2078 和 $0.2047 \mathrm{~nm}$, 而INI-TiO 中两 $^{-1}$ 键距离为 0.2074 和 $0.2044 \mathrm{~nm}$, 与 $\mathrm{TiO}_{2}$ 体材料中 $\mathrm{Ti}-\mathrm{O}$ 距离 $(0.1973 \mathrm{~nm})$ 相近, 说明两种敏化剂与 $\mathrm{TiO}_{2}$ 形成化学键并有较强的化学吸附作用. 这可以 进一步从图6中纯的 $\mathrm{TiO}_{2}$ 的态密度和染料 $-\mathrm{TiO}_{2}$ 体系 总态密度以及该体系中染料的投影态密度分布得 到证实. D5 和INI2 分布特征相似, 与纯 $\mathrm{TiO}_{2}$ 的态密 度相比, 由于染料的吸附, 在高于 $\mathrm{TiO}_{2}$ 的价带顶附近 有一些新的 $\pi$ 轨道的能级出现, 主要为染料的占据 轨道, 而LUMO主要由染料轨道贡献(图S3和图S4), 因此复合体系的能隙减小, 这种前线轨道分布的改

表2 D5, D9和INI1-9染料的电子注入驱动力 $\left(\Delta G_{\mathrm{inj}}\right)$, 染料再生驱动力 $\left(\Delta \boldsymbol{G}_{\mathrm{reg}}\right)$, 电荷复合驱动力 $\left(\Delta G_{\mathrm{rec}}\right)$, HOMO 能级 $\left(\boldsymbol{E}_{\text {номо }}\right)$ LUMO能级 $\left(\boldsymbol{E}_{\mathrm{LUMO}}\right)$ 和最大理论短路电流 $\left(J_{\mathbf{s c}}^{\max }\right)$

Table 2 Calculated electron injection driving force $\left(\Delta G_{\mathrm{inj}}\right)$, dye regeneration driving force $\left(\Delta G_{\mathrm{reg}}\right)$, charge recombination driving force $\left(\Delta G_{\text {rec }}\right)$, energy level of HOMO $\left(E_{\text {номо }}\right)$ and LUMO $\left(E_{\text {Luмо }}\right)$, and maximum theoretical short-circuit photocurrent density $\left(J_{\text {sc }}^{\max }\right)$ for D5, D9 and dyes IINI1-9

\begin{tabular}{ccccccc}
\hline Dye & $E_{\text {номо }} / \mathrm{eV}$ & $E_{\text {Lимо }} / \mathrm{eV}$ & $\Delta G_{\text {inj }} / \mathrm{eV}$ & $\Delta G_{\text {reg }} / \mathrm{eV}$ & $\Delta G_{\text {red }} / \mathrm{eV}$ & $J_{\text {sc }}^{\max } /\left(\mathrm{mA} \cdot \mathrm{cm}^{-2}\right)$ \\
\hline D5 & -5.09 & -2.67 & 1.33 & 0.25 & 1.09 & 9.78 \\
D9 & -4.85 & -2.57 & 1.43 & 0.01 & 0.85 & 10.98 \\
INI1 & -5.39 & -2.81 & 1.19 & 0.55 & 1.39 & 9.20 \\
INI2 & -5.07 & -2.59 & 1.41 & 0.23 & 1.07 & 13.26 \\
INI3 & -5.34 & -2.89 & 1.11 & 0.50 & 1.34 & 10.84 \\
INI4 & -5.19 & -2.80 & 1.20 & 0.35 & 1.19 & 10.52 \\
INI5 & -5.32 & -2.90 & 1.10 & 0.48 & 1.32 & 8.49 \\
INI6 & -5.27 & -2.86 & 1.14 & 0.43 & 1.27 & 8.38 \\
INI7 & -5.21 & -2.73 & 1.27 & 0.37 & 1.21 & 9.84 \\
INI8 & -5.32 & -2.84 & 1.16 & 0.48 & 1.32 & 8.00 \\
INI9 & -5.27 & -2.76 & 1.24 & 0.43 & 1.27 & 9.04 \\
\hline
\end{tabular}




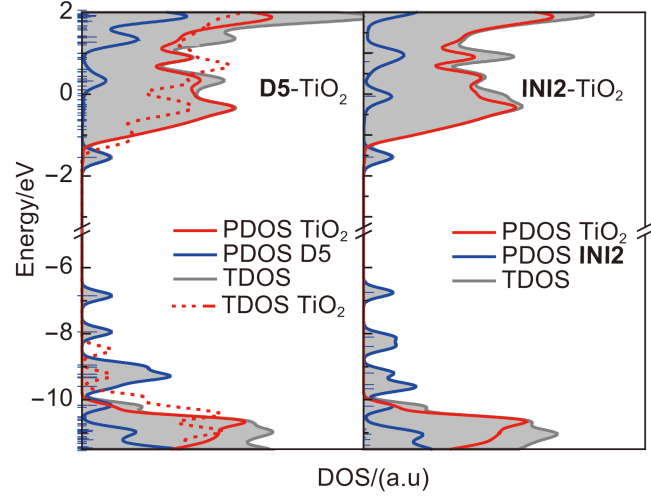

图6 $\mathrm{TiO}_{2}$ 态密度 $(\mathrm{DOS})\left(\right.$ 顶部)与 $\mathrm{D5}$ 和INI2 与 $\mathrm{TiO}_{2}$ 复合物总 态密度(TDOS) 以及投影态密度(PDOS)

Fig.6 Density of states (DOS) of bare $\mathrm{TiO}_{2}$ (on the top) and the total DOS (TDOS) and partial density of states (PDOS) of $\mathrm{D5}^{-\mathrm{TiO}_{2}}$ and $\mathrm{INI}_{2}-\mathrm{TiO}_{2}$ system

变将影响电子由染料到 $\mathrm{TiO}_{2}$ 的注入方式.

为避免高估电荷转移，采用 TD- $\omega \mathrm{B} 97 \mathrm{XD} / 6$ $31 \mathrm{~g}^{*}$ 方法结合PCM溶剂化模型计算了D5和INI2吸 附 $\mathrm{TiO}_{2}$ 后的电子吸收光谱, 计算拟合的电子吸收光 谱如图7所示, 表S2列出紫外可见区内振子强度较 大的激发态的跃迁能、振子强度、主要轨道贡献 及跃迁密度差图. D5- $\mathrm{TiO}_{2}$ 最大吸收峰在 $482 \mathrm{~nm}$, 与 实验上 ${ }^{18} \mathbf{D 5}-\mathrm{TiO}_{2}$ 在 $400-590 \mathrm{~nm}(2.1-3.1 \mathrm{eV})$ 范围内 展现出超过 $70 \%$ 光电转换效率一致. 与 D5- $-\mathrm{TiO}_{2}$ 相 比, INI2 $-\mathrm{TiO}_{2}$ 的最大吸收峰红移 $50 \mathrm{~nm}$, 从表 $\mathrm{S} 2$ 的结 果看出, 二者均由 $S_{0} \rightarrow S_{1}$ 态跃迁所致, 主要是 HOMO和HOMO-1轨道到LUMO轨道跃迁贡献, 而 这些轨道的电子密度主要定域在有机染料上(图 $\mathrm{S} 3$ 和图S4), 并没有明显的 $\mathrm{TiO}_{2}$ 轨道贡献. 因此, 可以 推断D5及INI2 染料以间接电子注入机理途径进行 电子转移, 即使在较高的激发态都发现有从染料到 $\mathrm{TiO}_{2}$ 的电荷转移跃迁, 如D5- $\mathrm{TiO}_{2}$ 复合物的 $S_{0} \rightarrow S_{7}$ 跃 迁及INI2- $\mathrm{TiO}_{2}$ 复合物的 $S_{0} \rightarrow S_{6}$ 跃迁, 但是他们的吸 收强度很弱. 值得注意的是, $\mathrm{INI}^{-}-\mathrm{TiO}_{2}$ 复合物的一 些中等吸收强度的高能激发态, 如 $S_{24} 、 S_{94}$ 和 $S_{95}$ 中有 明显的染料到 $\mathrm{TiO}_{2}$ 电荷转移, 尽管在紫外吸收区, 但 对提高IPCE也有一定贡献.

为验证结果可靠性, 我们采用同样方法计算两 种染料与 $\left(\mathrm{TiO}_{2}\right)_{48}$ 复合物的最低跃迁能. 如表 $\mathrm{S} 3$ 所示, 与 $\left(\mathrm{TiO}_{2}\right)_{9}$ 复合物结果相比，计算的D5 和INI2 与 $\left(\mathrm{TiO}_{2}\right)_{48}$ 复合物最大吸收波长分别红移了 26 和 $20 \mathrm{~nm}$, 其最大吸收均为 $S_{0} \rightarrow S_{1}$ 态跃迁, 这与 $\left(\mathrm{TiO}_{2}\right)_{9}$ 复合物结 果一致; 电荷密度差分结果表明二者跃迁主要为染
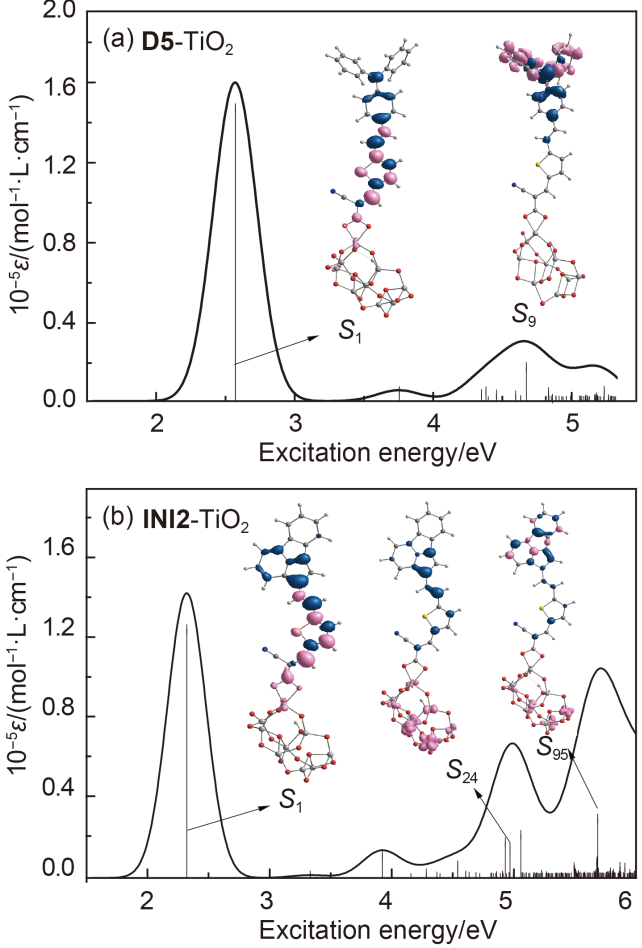

图7 在 $\omega \mathrm{B} 97 \mathrm{XD} / 6-31 \mathrm{~g}{ }^{*}$ 水平计算得到乙醇溶液中D5-

$\mathrm{TiO}_{2}(\mathrm{a})$ 和INI2- $\mathrm{TiO}_{2}(\mathrm{~b})$ 的电子吸收光谱和基态与特征激发 态之间的电荷密度差分图

Fig.7 Calculated electronic adsorption spectra and charge density difference between the ground state and the excited characteristic state for $\mathrm{D5}_{-}-\mathrm{TiO}_{2}$ (a) and $\mathrm{INI}_{2}-\mathrm{TiO}_{2}(\mathrm{~b})$ complexes at $\omega \mathrm{B} 97 \mathrm{XD} / 6-31 \mathrm{~g}^{*}$ level of theory in ethanol solvent

Pink and blue refer to an increase and an decrease of electron density, respectively; isovalue: 0.00002 a.u.

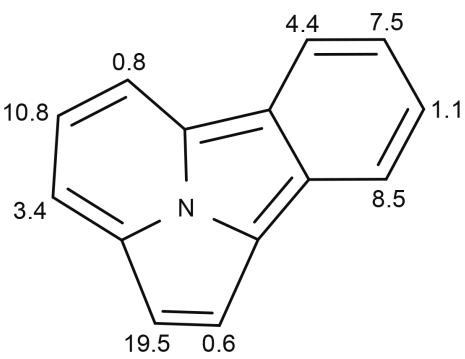

图8 B3LYP/6-31 $\mathrm{g}^{*}$ 方法计算INI芳环在乙醇溶液中的 Fukui亲核指数

Fig.8 Condensed Fukui nucleophilic function for the INI with $B 3 L Y P / 6-31 g^{*}$ method in ethanol solvent

料分子内的电荷转移跃迁, 进一步证实了上述间接 电子注入机理途径的结果.

\subsection{Fukui亲核反应指数}

概念密度泛函理论 52 可以通过反应活性指数大 小来预测化学反应的活性以及反应位点选择性. 为 
了预测INI系列染料中氮狮芳环桥联产物的合成难 易, 我们在B3LYP/6-31g*水平上计算了INI化合物的 亲核Fukui 反应指数 ${ }^{53,54}$ 来判断INI的亲核位点反应活 性大小. 图8计算结果表明, 亲核反应指数较大的中 氮狮芳环的位置是2位、4位和9位，最难发生亲核 反应的是环的 8 位、 5 位和 1 位，令人高兴的是， INI2 和INI4 在上述光捕获效率及短路等敏化剂的 性质中有较好的表现.

\section{4 结 论}

以D5和D9染料分子作为原型化合物, 考虑给体 芳环的不同桥联位置, 设计了9 个中氮狮INI为给体 的D- $\pi$-A型新型敏化剂. 通过DFT和TD-DFT计算表 征了 9 个中氮荫INI为给体的 $\mathrm{D}-\pi-\mathrm{A}$ 型新型敏化剂的 结构及染料敏化性能. 芳环不同桥联位置对分子的 前线轨道能级影响较大, 进而影响染料的电子吸收 光谱, 随芳环桥联位置不同, 体系的最大吸收位于 440-500 $\mathrm{nm}$ 可见区, 表现出明显的电荷分离特征, 2、3 和4位桥联INI2、INI3 和INI4 体系吸收波长比 D5更大, 因而具有较高的光捕获效率, 值得注意的 是, INI2 的最大理论短路电流比D9高 $2.3 \mathrm{~mA} \cdot \mathrm{cm}^{-2}$; 除INI2外，其他INI体系的电子注入驱动力相对 D5和D9较低而复合驱动力和再生驱动力 ${ }^{12}$ 相对略 高. D5、INI2 与 $\mathrm{TiO}_{2}$ 团簇复合物的结构和态密度结 果表明, 研究体系与 $\mathrm{TiO}_{2}$ 有较强的吸附作用. TD$\omega \mathrm{B} 97 \mathrm{XD} / 6-31 \mathrm{~g}$ "计算分析复合物可见光区最大吸收 峰为染料分子内 $\pi \rightarrow \pi$ *跃迁特征, 表明染料INI2 以间 接注入途径实现向半导体注入电子. Fukui反应指数 计算指出INI2 的亲核加成最易实现. D9的总光电转 换效率为 $6.9 \%,{ }^{18}$ 综合计算结果，可以预测敏化剂 INI2 将具有比D5和D9更好的光电转换效率, 当然, 为防止染料在半导体表面聚集而影响注入效率, 在 具体实验合成中需要考虑在芳环加上大的取代基, 而改变或增加共轭桥也可以进一步增强光谱吸收 及抑制暗电流和反向电子转移. $29,30,55$

Supporting Information: available free of charge via the internet at http://www.whxb.pku.edu.cn.

\section{References}

(1) O'Regan, B.; Grätzel, M. Nature 1991, 353 (6346), 737. doi: 10.1038/353737a0

(2) Yella, A.; Lee, H. W.; Tsao, H. N.; Yi, C.; Chandiran, A. K.; Nazeeruddin, M. K.; Diau, E. W. G.; Yeh, C. Y.; Zakeeruddin, S.
M.; Grätzel, M. Science 2011, 334 (6056), 629. doi: 10.1126/ science. 1209688

(3) Mishra, A.; Fischer, M. K. R.; Bäuerle, P. Angew. Chem. Int. Edit. 2009, 48 (14), 2474. doi: 10.1002/anie.v48:14

(4) He, J. J.; Chen, S. X.; Wang, T. T.; Zeng, H. P. Chin. J. Org Chem. 2012, 32 (3), 472. [何俊杰, 陈舒欣, 王婷婷, 曾和平. 有 机化学, 2012, 32 (3), 472.]

(5) Qu, S. Y.; Hua, J. L.; Tian, H. Sci. Sin. Chim. 2012, 42, 567. [翟 三寅, 花建丽, 田 禾. 中国科学: 化学, 2012, 42, 567.]

(6) Pei, J.; Liang, M.; Chen, J.; Tao, Z. L.; Xu, W. Acta Phys. -Chim. Sin. 2008, 24, 1950. [裴 娟, 梁 茂, 陈 军, 陶 占良, 许 炜. 物理化学学报, 2008, 24, 1950.] doi: 10.1016/S1872-1508(08)60077-7

(7) Wang, Z. S.; Cui, Y.; Hara, K.; Dan-oh, Y.; Kasada, C.; Shinpo, A. Adv. Mater. 2007, 19 (8), 1138. doi: 10.1002/adma. 200601020

(8) Sayama, K.; Hara, K.; Mori, N.; Satsuki, M.; Suga, S.; Tsukagoshi, S.; Abe, Y.; Sugihara, H.; Arakawa, H. Chem. Commun. 2000, 13, 1173. doi: 10.1039/b001517m

(9) Wu, W. J.; Yang, J. B.; Hua, J. L.; Tang, J.; Zhang, L.; Long, Y. T.; Tian, H. J. Mater. Chem. 2010, 20 (9), 1772. doi: 10.1039/b918282a

(10) Martinez-Diaz, M. V.; de la Torre, G.; Torres, T. Chem. Commun. 2010, 46 (38), 7090. doi: 10.1039/c0cc02213f

(11) Amacher, A.; Yi, C.; Yang, J.; Bircher, M. P.; Fu, Y.; Cascella, M.; Gratzel, M.; Decurtins, S.; Liu, S. X. Chem. Commun. 2014, 50 (49), 6540. doi: 10.1039/C4CC02696A

(12) Geng, Y.; Pop, F.; Yi, C.; Avarvari, N.; Gratzel, M.; Decurtins, S.; Liu, S. X. New J. Chem. 2014, 38 (7), 3269. doi: 10.1039/c4nj00428k

(13) Chen, X. M.; Jia, C. Y.; Wan, Z. Q.; Yao, X. J. Acta Phys. -Chim. Sin. 2014, 30, 273. [陈喜明, 贾春阳, 万中全, 姚小 军. 物理化学学报, 2014, 30, 273.] doi: 10.3866/PKU.WHXB 201311262

(14) Ito, S.; Zakeeruddin, S. M.; Humphry-Baker, R.; Liska, P.; Charvet, R.; Comte, P.; Nazeeruddin, M. K.; Péchy, P.; Takata, M.; Miura, H. Adv. Mater. 2006, 18 (9), 1202. doi: 10.1002/adma.200502540

(15) Wu, Y.; Marszalek, M.; Zakeeruddin, S. M.; Zhang, Q.; Tian, H.; Grätzel, M.; Zhu, W. Energy Environ. Sci. 2012, 5 (8), 8261. doi: $10.1039 / \mathrm{c} 2 \mathrm{ee} 22108 \mathrm{j}$

(16) Mitsumori, T.; Bendikov, M.; Dautel, O.; Wudl, F.; Shioya, T.; Sato, H.; Sato, Y. J. Am. Chem. Soc. 2004, 126 (51), 16793. doi: 10.1021/ja049214x

(17) Hagberg, D. P.; Edvinsson, T.; Marinado, T.; Boschloo, G.; Hagfeldt, A.; Sun, L. Chem. Commun. 2006, 2245. doi: 10.1039/b603002e

(18) Hagberg, D. P.; Yum, J. H.; Lee, H.; De Angelis, F.; Marinado, T.; Karlsson, K. M.; Humphry-Baker, R.; Sun, L.; Hagfeldt, A.; Grätzel, M.; Nazeeruddin, M. K. J. Am. Chem. Soc. 2008, 130. doi: $10.1021 / \mathrm{ja} 800066 \mathrm{y}$

(19) Becke, A. D. J. Chem. Phys. 1993, 98 (7), 5648. doi: 10.1063/ 


\subsection{3}

(20) Perdew, J. P.; Burke, K.; Ernzerhof, M. Physical Review Letters 1996, 77 (18), 3865. doi: 10.1103/PhysRevLett.77.3865

(21) Lynch, B. J.; Fast, P. L.; Harris, M.; Truhlar, D. G. J. Phys. Chem. A 2000, 104 (21), 4811. doi: 10.1021/jp000497z

(22) Zhao, Y.; Truhlar, D. G. J. Phys. Chem. A 2006, 110 (15), 5121

(23) Yanai, T.; Tew, D. P.; Handy, N. C. Chem. Phys. Lett. 2004, 393 (1-3), 51. doi: 10.1016/j.cplett.2004.06.011

(24) Tawada, Y.; Tsuneda, T.; Yanagisawa, S.; Yanai, T.; Hirao, K. J. Chem. Phys. 2004, 120 (18), 8425. doi: 10.1063/1.1688752

(25) Chai, J. D.; Head-Gordon, M. Phys. Chem. Chem. Phys. 2008, 10 (44), 6615. doi: 10.1039/b810189b

(26) Barone, V.; Cossi, M. J. Phys. Chem. A 1998, 102 (11), 1995. doi: $10.1021 /$ jp9716997

(27) Lu, T.; Chen, F. J. Comput. Chem. 2012, 33 (5), 580. doi: $10.1002 / j c c . v 33.5$

(28) Sanchez-de-Armas, R.; San Miguel, M. A.; Oviedo, J.; Sanz, J. F. Phys. Chem. Chem. Phys. 2012, 14 (1), 225. doi: 10.1039/C1CP22058F

(29) Zhang, J.; Li, H.B.; Sun, S. L.; Geng, Y.; Wu, Y.; Su, Z. M. J. Mater. Chem. 2012, 22 (2), 568. doi: 10.1039/C1JM13028E

(30) Zhang, J.; Kan, Y. H.; Li, H. B.; Geng, Y.; Wu, Y.; Su, Z. M. Dyes Pigments 2012, 95 (2), 313. doi: 10.1016/j.dyepig. 2012.05.020

(31) Pastore, M.; Angelis, F. D. ACS Nano 2009, 4 (1), 556. doi: 10.1021/nn901518

(32) Soler, J. M.; Artacho, E.; Gale; J. D.; García, A.; Junquera, J.; Ordejón, P.; Sánchez-Portal, D. J. Phys.: -Condes. Matter 2002, 14 (11), 2745. doi: 10.1088/0953-8984/14/11/302

(33) Ordejón, P.; Artacho, E.; Soler, J. M. Phys. Rev. B 1996, 53 (16), R10441.

(34) Gratzel, M. Nature 2001, 414 (6861), 338.

(35) Cahen, D.; Hodes, G.; Grätzel, M.; Guillemoles, J. F.; Riess, I. J. Phys. Chem. B 2000, 104 (9), 2053. doi: 10.1021/jp993187t

(36) Kim, B. G.; Zhen, C. G.; Jeong, E. J.; Kieffer, J.; Kim, J. $A d v$. Funct. Mater. 2012, 22 (8), 1606. doi: 10.1002/adfm.v22.8

(37) Jacquemin, D.; Perpète, E. A.; Scuseria, G. E.; Ciofini, I.; Adamo, C. J. Chem. Theory. Comput. 2008, 4 (1), 123.

(38) Dreuw, A.; Head-Gordon, M. J. Am. Chem. Soc. 2004, 126 (12),
4007. doi: 10.1021/ja039556n

(39) Fabian, J. Theor. Chem. Acc. 2001, 106 (3), 199. doi: $10.1007 / \mathrm{s} 002140100250$

(40) Laurent, A. D.; Jacquemin, D. Int. J. Quantum Chem. 2013, 113 (17), 2019. doi: 10.1002/qua.24438

(41) Pastore, M.; Mosconi, E.; De Angelis, F.; Grätzel, M. J. Phys. Chem. C 2010, 114 (15), 7205. doi: 10.1021/jp100713r

(42) Laurent, A. D.; Adamo, C.; Jacquemin, D. Phys. Chem. Chem. Phys. 2014, 16 (28), 14334. doi: 10.1039/c3cp55336a

(43) Zhan, W. S.; Pan, S.; Li Y. Z.; Chen, M. D. Acta Phys. -Chim. Sin. 2010, 26 (5), 1408. [詹卫伸, 潘 石, 李源作, 陈茂笃. 物理 化学学报, 2010, 26 (5), 1408.] doi: 10.1039/c3cp55336a

(44) Zhan, W. S.; Li, R.; Pan, S.; Guo, Y. N.; Zhang, Y. Acta Phys. -Chim. Sin. 2013, 29, 255. [詹卫伸, 李 睿, 潘 石, 郭英 楠, 张 毅. 物理化学学报, 2013, 29, 255.] doi: 10.3866/PKU .WHXB201211221

(45) Le Bahers, T.; Adamo, C.; Ciofini, I. J. Chem. Theory. Comput. 2011, 7 (8), 2498. doi: 10.1021/ct200308m

(46) Grätzel, M. Accounts Chem. Res. 2009, 42 (11), 1788. doi: 10.1021/ar900141y

(47) Vlachopoulos, N.; Liska, P.; Augustynski, J.; Grätzel, M. J. Am. Chem. Soc. 1988, 110 (4), 1216. doi: 10.1021/ja00212a033

(48) Jiao, Y.; Ma, W.; Meng, S. Chem. Phys. Lett. 2013, 586, 97.

(49) Zhang, J. Z.; Zhang, J.; Li, H. B.; Wu, Y.; Xu, H. L.; Zhang, M.; Geng, Y.; Su, Z. M. J. Power Sources 2014, 267, 300.

(50) Ma, W.; Jiao, Y.; Meng, S. J. Phys. Chem. C 2014, 118 (30), 16447. doi: 10.1021/jp410982e

(51) Daeneke, T.; Mozer, A. J.; Uemura, Y.; Makuta, S.; Fekete, M.; Tachibana, Y.; Koumura, N.; Bach, U.; Spiccia, L. J. Am. Chem. Soc. 2012, 134 (41), 16925. doi: 10.1021/ja3054578

(52) Liu, S. B. Acta Phys. -Chim. Sin. 2009, 25, 590. [刘述斌. 物理化 学学报, 2009, 25, 590.] doi: 10.3866/PKU.WHXB20090332

(53) Parr, R. G.; Yang, W. J. Am. Chem. Soc. 1984, 106 (14), 4049. doi: $10.1021 / \mathrm{ja} 00326 \mathrm{a} 036$

(54) Makedonas, C.; Mitsopoulou, C. A. European Journal of Inorganic Chemistry 2006, 2006 (3), 590.

(55) Clifford, J. N.; Palomares, E.; Nazeeruddin, M. K.; Grätzel, M.; Nelson, J.; Li, X.; Long, N. J.; Durrant, J. R. J. Am. Chem. Soc. 2004, 126 (16), 5225. doi: 10.1021/ja039924n 
Supplementary Information for Acta Phys. -Chim. Sin. 2015, 31 (8), 1504-1512 doi: 10.3866/PKU.WHXB201505211

\title{
含中氮狮有机太阳能电池染料敏化剂的分子设计
}

\author{
侯丽梅 $^{1,2}$ 温 智 ${ }^{2,3}$ 李银祥 $^{2}$ 胡华友 $^{2}$ 阚玉和 ${ }^{2,3, *}$ \\ 苏忠民 $1,3, *$ \\ ( ${ }^{1}$ 延边大学理学院化学系, 吉林 延吉 $133002 ;{ }^{2}$ 江苏省低维材料化学重点建设实验室, 淮阴师范学院化 \\ 学化工学院, 江苏 淮安 $223300 ;{ }^{3}$ 东北师范大学化学学院, 功能材料化学研究所, 长春 130024)
}

\section{Molecular Design of Indolizine Derivative as Sensitizers for Organic Dye-Sensitized Solar Cells}

\author{
HOU Li-Mei ${ }^{1,2}$ \\ WEN Zhi' ${ }^{2,3}$ \\ LI Yin-Xiang ${ }^{2}$ \\ HU Hua-You ${ }^{2}$ \\ KAN Yu-He $e^{2,3, *}$ \\ SU Zhong-Min ${ }^{1,3, *}$ \\ ( ${ }^{1}$ Department of Chemistry, School of Science and Engineering, Yanbian University, Yanji 133002, Jilin Province, \\ P. R. China; ${ }^{2}$ Jiangsu Province Key Laboratory for Chemistry of Low-Dimensional Materials, School of \\ Chemistry and Chemical Engineering, Huaiyin Normal University, Huai'an 223300, Jiangsu Province, P. R. \\ China; ${ }^{3}$ Institute of Functional Material Chemistry, Faculty of Chemistry, Northeast Normal University, \\ Changchun 130024, P. R. China)
}


Table S1 Computed the length of CT ( $D_{\mathrm{CT}}$ in $\AA$ ), transition dipole moment $\mu_{e g}$ (a. u.), and spatial overlap index ( $\Lambda$ ) of D5, D9 and INI1- INI 9 in ethanol solvent

\begin{tabular}{ccccccc}
\hline & \multicolumn{3}{c}{ B3LYP } & \multicolumn{3}{c}{$\omega$ B97XD } \\
\cline { 2 - 7 } D5 & $D_{\mathrm{CT}}$ & $\Lambda$ & $\mu_{e g}$ & $D_{\mathrm{CT}}$ & $\Lambda$ & $\mu_{e g}$ \\
D9 & 6.2 & 0.782 & 21.6 & 4.2 & 0.889 & 23.6 \\
INI-1 & 6.5 & 0.762 & 22.0 & 4.4 & 0.878 & 24.8 \\
INI-2 & 5.2 & 0.750 & 19.3 & 3.0 & 0.919 & 17.1 \\
INI-3 & 4.6 & 0.837 & 25.5 & 3.9 & 0.878 & 24.7 \\
INI-4 & 5.7 & 0.784 & 18.0 & 3.5 & 0.914 & 17.9 \\
INI-5 & 5.8 & 0.770 & 17.8 & 4.2 & 0.876 & 20.7 \\
INI-6 & 5.3 & 0.758 & 17.1 & 3.0 & 0.921 & 10.5 \\
INI-7 & 5.7 & 0.727 & 10.8 & 3.4 & 0.897 & 14.0 \\
INI-8 & 6.2 & 0.777 & 18.2 & 4.0 & 0.891 & 22.6 \\
INI-9 & 6.8 & 0.743 & 21.1 & 3.2 & 0.922 & 21.9 \\
\hline
\end{tabular}

Table S2 Calculated the lowest excitation energy ( $E$, in eV), absorption wavelength $(\lambda$ in $\mathbf{n m})$, oscillator strength $(f)$ and transition nature of D5-( $\left.\mathrm{TiO}_{2}\right)_{9}$ and $\mathrm{INI}_{2}-\left(\mathrm{TiO}_{2}\right)_{9}$ at PCM- $\omega \mathrm{B97XD}$ $/ 6-31 g^{*}$ level of theory in ethanol solvent

\begin{tabular}{|c|c|c|c|c|c|}
\hline State & $E$ & $\lambda$ & $f$ & Transition contributions & $\mathrm{CDD}^{\mathrm{a}}$ \\
\hline & & & & D5- $\left(\mathrm{TiO}_{2}\right)_{9}$ & \\
\hline $\mathrm{S}_{0} \rightarrow \mathrm{S}_{1}$ & 2.57 & 482 & 2.2562 & $\mathrm{H}-1 \rightarrow \mathrm{L}(21 \%), \mathrm{H} \rightarrow \mathrm{L}(70 \%)$ & \\
\hline $\mathrm{S}_{0} \rightarrow \mathrm{S}_{2}$ & 3.75 & 330 & 0.0771 & $\begin{array}{l}\mathrm{H}-4 \rightarrow \mathrm{L}(10 \%), \mathrm{H}-1 \rightarrow \mathrm{L} \\
(50 \%), \mathrm{H} \rightarrow \mathrm{L}+18(14 \%)\end{array}$ & \\
\hline $\mathrm{S}_{0} \rightarrow \mathrm{S}_{3}$ & 4.35 & 285 & 0.0560 & $\mathrm{H}-7 \rightarrow \mathrm{L}(86 \%)$ & \\
\hline $\mathrm{S}_{0} \rightarrow \mathrm{S}_{4}$ & 4.38 & 283 & 0.0771 & $\begin{array}{l}\mathrm{H} \rightarrow \mathrm{L}(10 \%), \mathrm{H} \rightarrow \mathrm{L}+18(25 \%), \\
\mathrm{H} \rightarrow \mathrm{L}+29(15 \%)\end{array}$ & \\
\hline $\mathrm{S}_{0} \rightarrow \mathrm{S}_{6}$ & 4.46 & 278 & 0.0528 & $\mathrm{H} \rightarrow \mathrm{L}+29(41 \%)$ & \\
\hline $\mathrm{S}_{0} \rightarrow \mathrm{S}_{7}$ & 4.60 & 270 & 0.0453 & $\begin{array}{l}\mathrm{H} \rightarrow \mathrm{L}+1(21 \%), \mathrm{H} \rightarrow \mathrm{L}+3 \\
(14 \%), \mathrm{H} \rightarrow \mathrm{L}+5(15 \%)\end{array}$ & \\
\hline
\end{tabular}




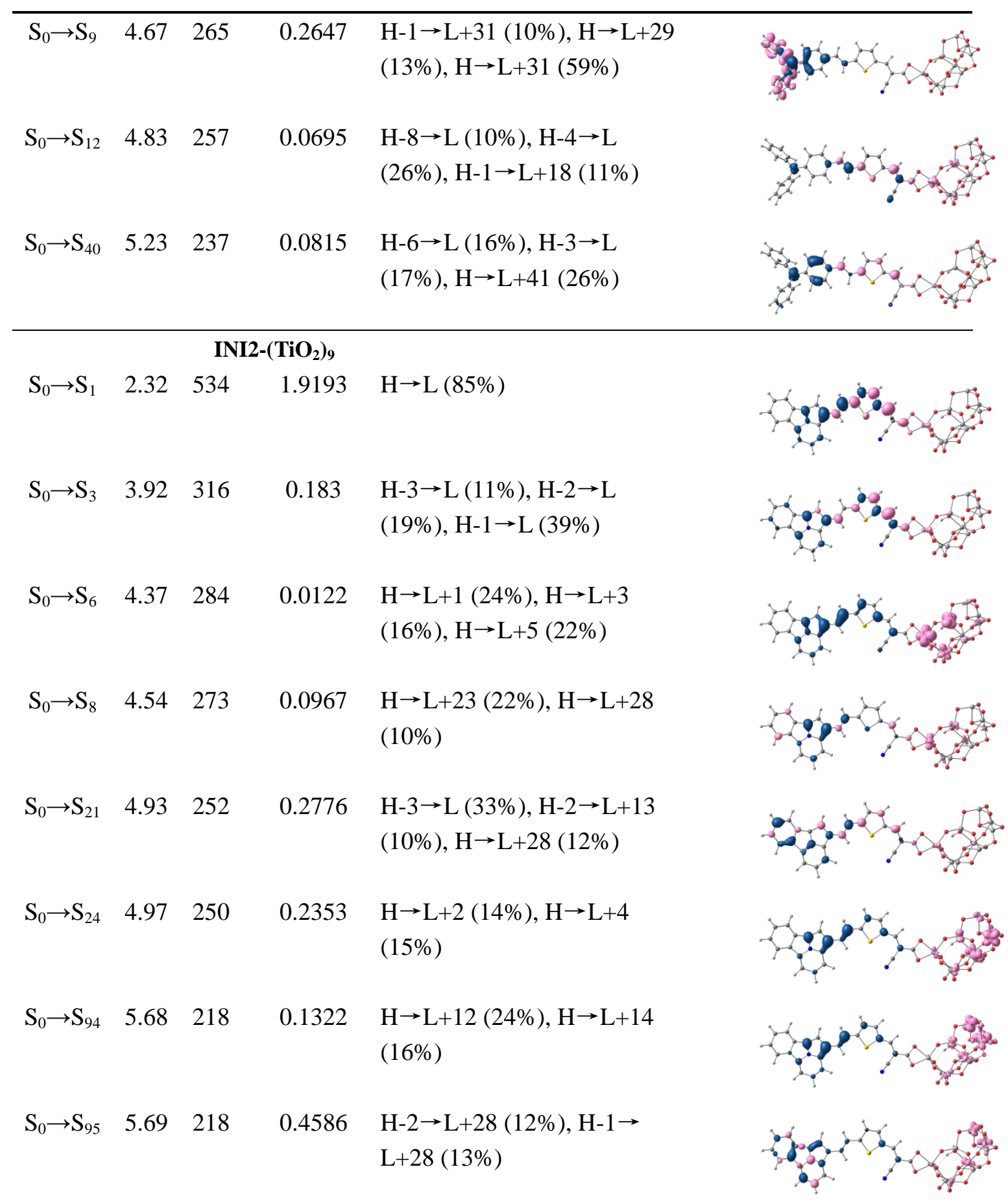

${ }^{\mathrm{a}}$ charge difference density(contour value 0.001258 a.u.) 
Table S3 Calculated the lowest excitation energy $(E$, in eV), absorption wavelength $(\lambda$ in $\mathbf{n m})$, oscillator strength $(f)$ and transition nature of D5-( $\left.\mathrm{TiO}_{2}\right)_{48}$ and $\mathrm{INI} 2-\left(\mathrm{TiO}_{2}\right)_{48}$ at PCM- $\omega \mathrm{B97XD}$ $/ 6-31 \mathrm{~g} *$ level of theory in ethanol solvent

\begin{tabular}{lllll}
\hline State & $E$ & $\lambda$ & $f$ & $\begin{array}{c}\text { Transition } \\
\text { contributions }\end{array}$ \\
\hline
\end{tabular}

D5- $\left(\mathrm{TiO}_{2}\right)_{48}$

$\begin{array}{ccccc}\mathrm{S}_{0} \rightarrow \mathrm{S} & & & & \mathrm{H}-1 \rightarrow \mathrm{L}(19 \%), \mathrm{H} \rightarrow \\ 1 & 2.44 & 508 & 2.4316 & \mathrm{~L}(68 \%)\end{array}$

INI2- $\left(\mathrm{TiO}_{2}\right)_{48}$

$\mathrm{S}_{0} \rightarrow \mathrm{S}_{1} 2.23 \quad 554 \quad 2.0658 \quad \mathrm{H} \rightarrow \mathrm{L}(80 \%)$

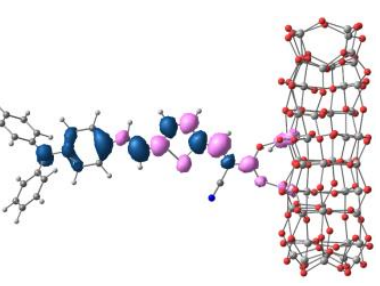

$\mathrm{S}_{0} \rightarrow \mathrm{S}_{1} \quad 2.23 \quad 554 \quad 2.0658 \quad \mathrm{H} \rightarrow \mathrm{L}(80 \%)$

${ }^{\mathrm{a}}$ charge difference density(contour value 0.001258 a.u.)

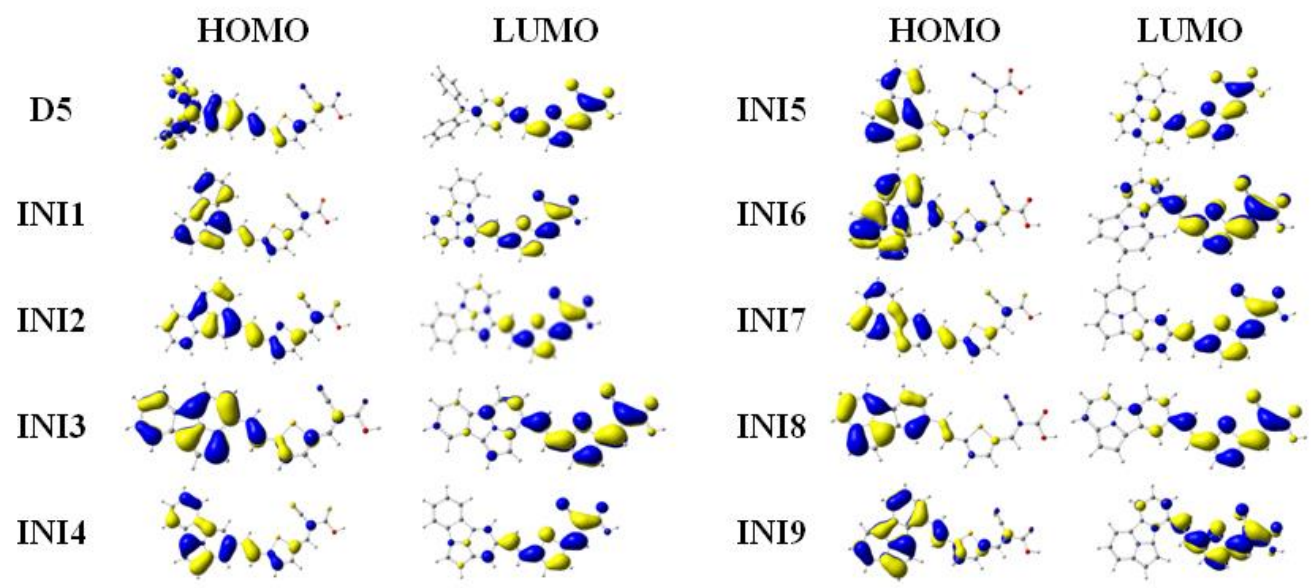

Fig.S1 Frontier molecular orbitals (isovalue 0.03 a.u.) of D5 and INI1-9 at $\omega$ B97XD /6-31g*

level 


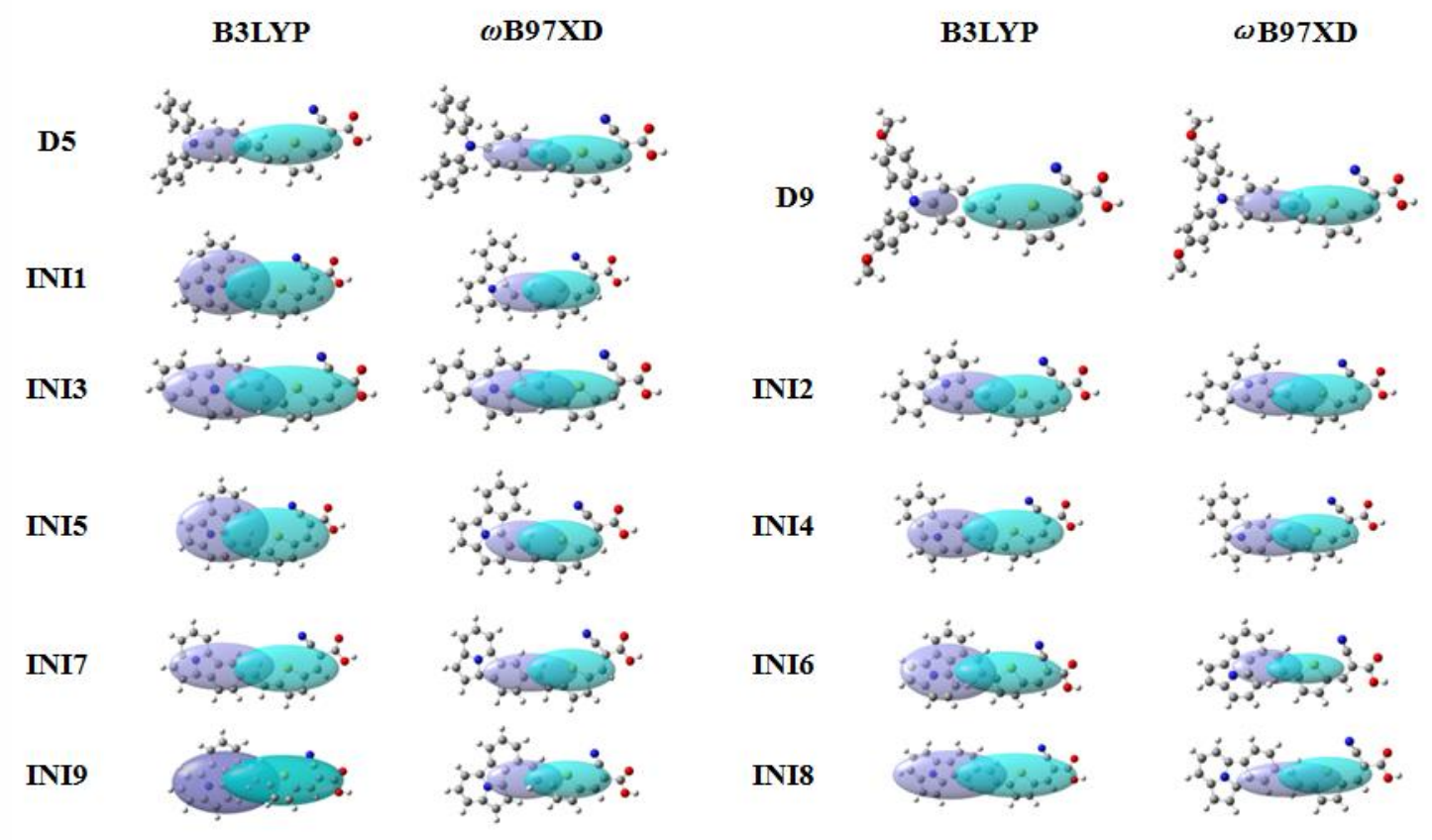

Fig. S2 Computed centroids of charge $C_{\text {. }}$ (blue) and $C_{+}$(green) of D5, D9 and INI1- INI9

(isocontour value 0.00055 a.u.) 


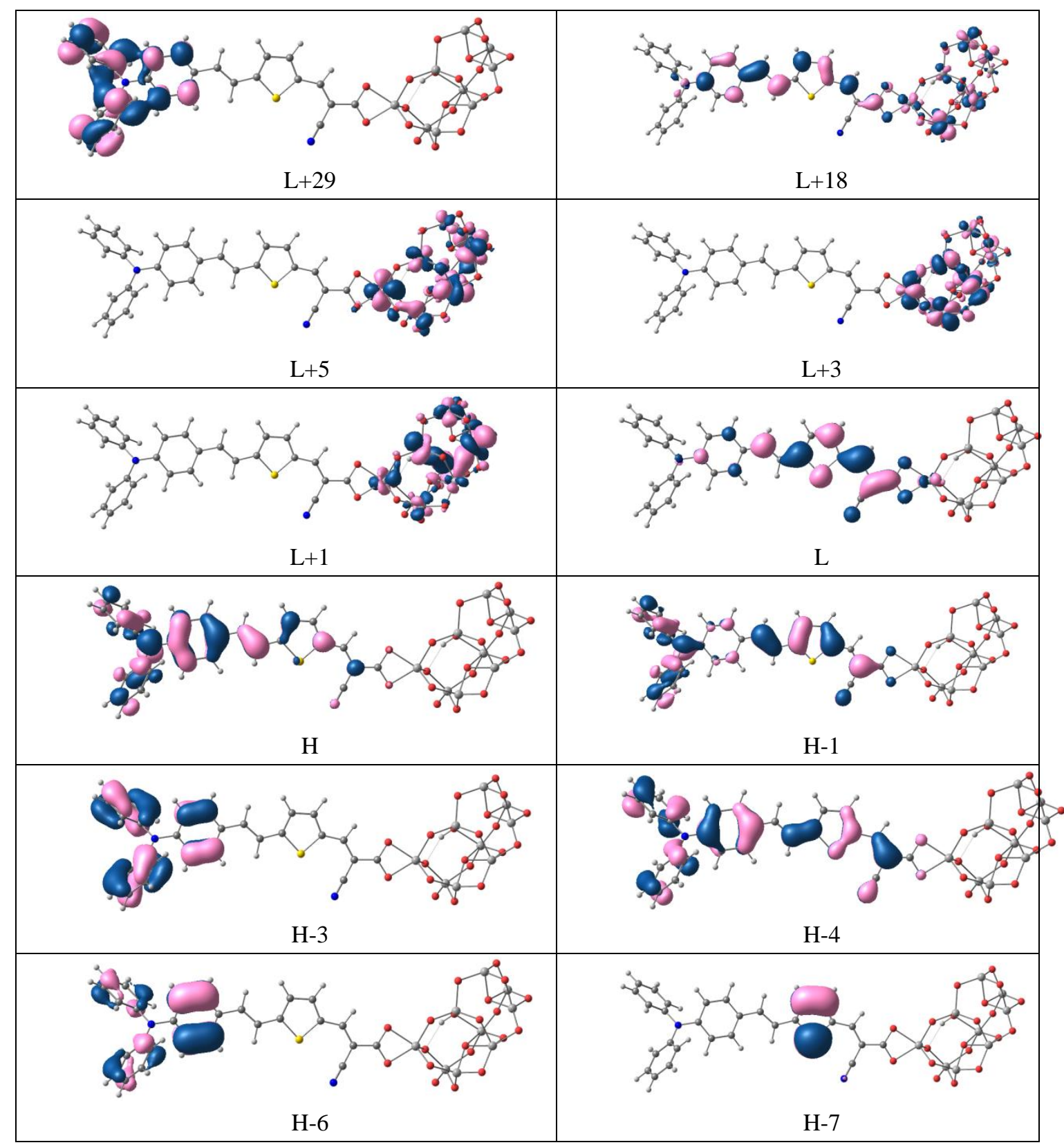

Fig.S3 Relative MOs of the excited state for D5- $\left(\mathrm{TiO}_{2}\right)_{9}$ 


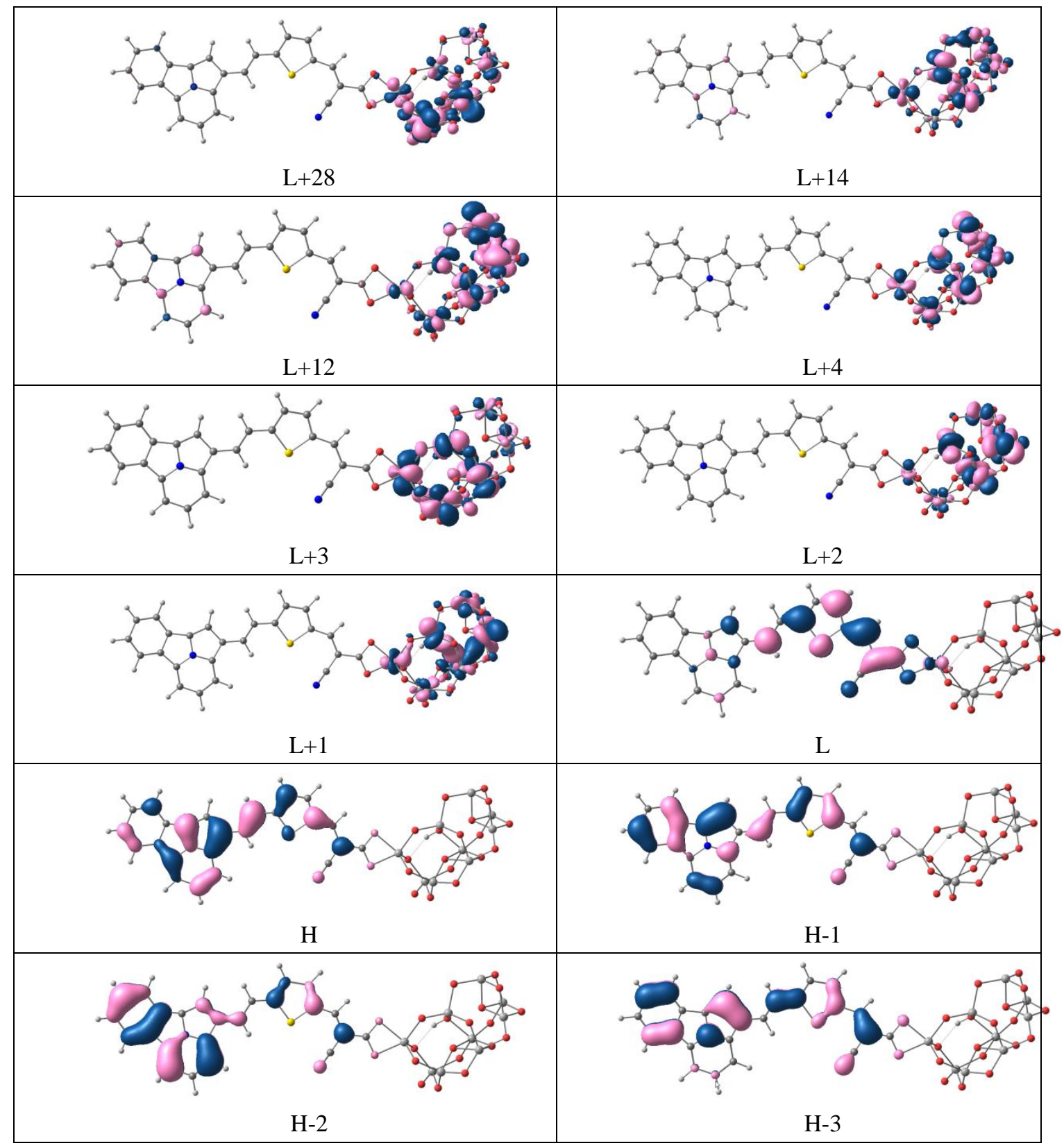

Fig.S4 Relative MOs of the excited state for INI2-( $\left.\mathrm{TiO}_{2}\right)_{9}$ 